\title{
Optimization and Composition of Volatile Oil from Polygonatum odoratum (Mill Druce) using Supercritical Fluid Extraction
}

\author{
Xiuhong Zhao ${ }^{1 *}$, Jie Zeng ${ }^{2}$, Haiyan $\mathrm{Gao}^{2}$ and Ying Wang ${ }^{3}$ \\ ${ }^{1}$ Grain College, Shen Yang Normal University, Shenyang 110034, ${ }^{2}$ School of Food Science, Henan Institute of Science and \\ Technology, Xinxiang 453003, ${ }^{3}$ Institute of Applied Ecology, Chinese Academy of Sciences, Shenyang 110016, China
}

*For correspondence: Email: zhaoxiuhong1976@aliyun.com; Tel: +86-24-8650-6009

\begin{abstract}
Purpose: To determine the effects of temperature, pressure and extraction time on oil yield obtained from Polygonatum odoratum as well as the optimum processing conditions for supercritical carbon dioxide $\left(\mathrm{CO}_{2}\right)$ extraction.

Methods: Supercritical $\mathrm{CO}_{2}$ extraction technology was adopted in this experiment to study the process of extraction of volatile oil from Polygonatum odoratum while gas chromatograph-mass spectrometer (GC-MS) technique was employed to analyze the chemical composition of the volatile oil. Response surface methodology (RSM) was applied to optimize supercritical $\mathrm{CO}_{2}$ process conditions.

Results: The determined optimal conditions were as follows: extraction pressure, $27 \mathrm{MPa}$; extraction temperature, $50{ }^{\circ} \mathrm{C}$; and extraction time, $97.10 \mathrm{~min}$. Under these conditions, the predicted yield of Polygonatum volatile oil was $2.04 \%$ as against an actual oil yield of $2.02 \%$ of the seeds. GC-MS analysis showed that the extract obtained by supercritical $\mathrm{CO}_{2}$ extraction was richer in fatty acids and flavoring substances than that obtained by hydrodistillation.

Conclusion: Using RSM can optimize conditions of Polygonatum volatile oil. This provides a scientific basis for further research and development of healthy foods, as well as comprehensive utilization of Polygonatum odoratum.
\end{abstract}

Keywords: Polygonatum odoratum, Volatile oil, Supercritical fluid, Carbon dioxide, Extraction, Gas chromatograph-mass spectrometer

Tropical Journal of Pharmaceutical Research is indexed by Science Citation Index (SciSearch), Scopus, International Pharmaceutical Abstract, Chemical Abstracts, Embase, Index Copernicus, EBSCO, African Index Medicus, JournalSeek, Journal Citation Reports/Science Edition, Directory of Open Access Journals (DOAJ), African Journal Online, Bioline International, Open-J-Gate and Pharmacy Abstracts

\section{INTRODUCTION}

Polygonatum, also called yuzhu, waisheng, weirui, or lingdangcai in Chinese language, originated in the Southwest region of China and is well distributed in the wild. It can also be found across the southern United States [1]. Its root, mild natured and sweet tasting, can be used as a medicine. Recent clinical research has shown that Polygonatum can be used to cure diseases such as fever, asthenic fever, dry cough, cardiopathy, diabetes and tuberculosis [1-3].

Volatile oils obtained from natural sources are of great value in the cosmetic, pharmaceutical and food industries owing to their sensorial properties [4]. Polygonatum volatile oil, also called Polygonatum essential oil, is one of the major functional components of Polygonatum. It contains various kinds of active ingredients, applicable to not only in the clinical 
biopharmaceutical industry, but also the cosmetic industry [5]. Volatile oils are stored in specific secretory structures and can be extracted from leaves, flowers and seeds of the plants [6].

Although solvent extraction [7,8] and steam distillation [9] are the commonly used methods to extract volatile oil from natural sources, they have undeniable deficiencies, such as solvent residues, low extraction rates, hydrolysis phenomena and thermal degradation [10]. Supercritical fluid extraction is widely used for extraction of flavours and fragrances [11,12]. Carbon dioxide is usually selected as a solvent in supercritical fluid extraction (SFE) due to its relatively low critical pressure (7.4 MPa) and low critical temperature $\left(32{ }^{\circ} \mathrm{C}\right)$, perfectly non-toxic, chemically unreactive, and is easily available in high purity at relatively low cost and it can also be easily removed from the extracts [13]. Compared with steam distillation, the extract from SFE can better maintain the effective ingredients and taste of medicinal plants with no solvent residue, so the extract is very close to its natural state with no harmful substances to humans and the environment [14].

The main objective of the study was to determine the effects of temperature, pressure and extraction time on oil yield obtained from Polygonatum odoratum and to find the optimum processing condition for supercritical $\mathrm{CO}_{2}$ extraction, which could provide a foundation for further research and comprehensive utilization of Polygonatum resources.

\section{EXPERIMENTAL}

\section{Plant material}

Polygonatum was purchased from a local market inLiaoning Province of China in 2011 and authenticated by Professor liu Changjiang of Shenyan Agricultural University. Polygonatum chip was dried in the drying oven at $45{ }^{\circ} \mathrm{C}$, crushed and sifted through a $0.63 \mathrm{~mm}$ aperture sized sieve.

\section{Apparatus and equipment}

The supercritical $\mathrm{CO}_{2}$ extraction apparatus used was a provided by Jiangsu Nantong Hua'an Supercritical Extraction Co, Ltd (model HA-22150-06), with an extraction column (2 L), separator I, separator II (0.6 L), max. extraction temp of 75 ${ }^{\circ} \mathrm{C}$, max. extraction pressure of $50 \mathrm{MPa}$, max. flow rate of $50 \mathrm{~L} / \mathrm{h}$, and $\mathrm{CO}_{2}$ purity of $99 \%$.
Workflow was consistent with that described by Wei et al [15].

\section{Supercritical $\mathrm{CO}_{2}$ extraction}

Process flow: Placed $300 \mathrm{~g}$ of polygonatum powder into the extraction kettle, where it was heated to a required temperature. Then, opened the gas inlet valve, started the high pressure pump and adjusted the valve to extract. After that, collected extracts (volatile oil), and closed the gas inlet valve. After all the above were done, opened the outlet valve and cooled. The last process was to turn off the equipment.

Different pressures $(15,20,25$, and $30 \mathrm{MPa})$, treatment times $(30,60,90,120$, and $150 \mathrm{~min})$ and kettle temperature $\left(35,40,45\right.$, and $\left.50{ }^{\circ} \mathrm{C}\right)$ were used to investigate the optimal extraction conditions of polygonatum extracts (volatile oil) according to its extraction rate and oil yield. The conditions for high extraction rate were determined in accordance with the results of the single factor test.

\section{Conditions for GC-MS analysis}

The GC-MS analysis in this work was carried out by using a Thermo Finnigan Trace GC/Trace DSQ/AS3000 (EI, Quadrapole) equipped with a DB-5MS fused silica capillary column (30 $\mathrm{m} \times$ $0.25 \mathrm{~mm}$ i.d., $0.25 \mu \mathrm{m}$ thickness of phenyl arylene polymer film). Diluted samples (1/1000, in $\mathrm{CHCl}_{3}$ ) of $1 \mu \mathrm{L}$ were injected manually in the splitless mode. The injection port, MS interface and the ion source temperatures were set as 240 ${ }^{\circ} \mathrm{C}, 280{ }^{\circ} \mathrm{C}$ and $230{ }^{\circ} \mathrm{C}$ respectively. Helium was selected as the carrier gas at a flow rate of 1 $\mathrm{mL} / \mathrm{min}$. For a good separation, the GC oven temperature was programmed from $80^{\circ} \mathrm{C}$ to 160 ${ }^{\circ} \mathrm{C}$ at $4.5{ }^{\circ} \mathrm{C} / \mathrm{min}$, then held isothermally for 10 min, and raised to $240{ }^{\circ} \mathrm{C}$ at $4.5^{\circ} \mathrm{C} / \mathrm{min}$. For GCMS detection, an electron ionization (EI) system with ionization energy of $70 \mathrm{eV}$ was used in this work. Mass scanning range $(\mathrm{m} / \mathrm{z})$ was $40 \sim 450$ amu. The identification of individual compounds was based on matching their mass spectra with standard spectral libraries (version 98, NIST mass spectral library) and published data.

\section{Response surface methodology design}

Response surface methodology (RSM) was used to determine the optimum levels of temperature, pressure and extraction time to increase yield. The coded and uncoded independent variables used in RSM design are shown in Table 1. 
Table 1: Uncoded and coded independent variables used in RSM design for optimization studies

\begin{tabular}{lcccc}
\hline Symbol & Independent & \multicolumn{3}{c}{ Coded level } \\
\cline { 3 - 5 } & variable & $\mathbf{- 1}$ & $\mathbf{0}$ & $\mathbf{1}$ \\
\hline $\mathrm{X} 1$ & Temperature $\left({ }^{\circ} \mathrm{C}\right)$ & 40 & 45 & 50 \\
X2 & Pressure $(\mathrm{MPa})$ & 20 & 25 & 30 \\
$\mathrm{X} 3$ & Time (min) & 60 & 90 & 120 \\
\hline
\end{tabular}

For convenience of notation and solving for coefficients in the matrix, actual Xi variables were coded as 1, 0, +1 (Table 1). The study was carried out according to Box Benken design and the experimental points used according to this design are shown in Table 2 [16].

\section{Statistical analysis}

The data obtained in this study were expressed as the mean of three replicate determinations and standard deviation (SD). Statistical comparisons were made using Student's test. $p$ $<0.05$ was considered statistically significant.

\section{RESULTS}

\section{Oil yield}

Operating conditions of $45^{\circ} \mathrm{C}, 30 \mathrm{MPa}, 150 \mathrm{~min}$ were initially established for SFE and common operational conditions were adopted for the hydrodistillation (HD) method in this study. The study investigated and compared the oil yields under the above-mentioned operational conditions.

Table 2: Experimental points of the Box Benken design and the experimental data

\begin{tabular}{lcccc}
$\begin{array}{l}\text { Test } \\
\text { no. }\end{array}$ & $\begin{array}{c}\text { Temperature } \\
\left(\mathbf{X}_{\mathbf{1}}\right)\end{array}$ & $\begin{array}{c}\text { Pressure } \\
\left(\mathbf{X}_{\mathbf{2}}\right)\end{array}$ & $\begin{array}{c}\text { Time } \\
\left(\mathbf{X}_{\mathbf{3}}\right)\end{array}$ & $\begin{array}{c}\text { Oil } \\
\text { yield } \\
(\%)\end{array}$ \\
\hline 1 & +1 & +1 & 0 & 1.94 \\
2 & +1 & -1 & 0 & 1.66 \\
3 & +1 & 0 & +1 & 1.93 \\
4 & +1 & 0 & -1 & 1.83 \\
5 & 0 & +1 & +1 & 1.85 \\
6 & 0 & -1 & +1 & 1.40 \\
7 & 0 & +1 & -1 & 1.79 \\
8 & 0 & -1 & -1 & 1.52 \\
9 & -1 & +1 & 0 & 1.83 \\
10 & -1 & -1 & 0 & 1.48 \\
11 & -1 & 0 & +1 & 1.80 \\
12 & -1 & 0 & -1 & 1.78 \\
13 & 0 & 0 & 0 & 1.93 \\
14 & 0 & 0 & 0 & 1.96 \\
15 & 0 & 0 & 0 & 1.96 \\
16 & 0 & 0 & 0 & 1.93 \\
17 & 0 & 0 & 0 & 1.92 \\
\hline
\end{tabular}

Table 3: Composition of volatile oil obtained by hydrodistillation (HD) and supercritical fluid extraction (SFE)

\begin{tabular}{|c|c|c|c|c|c|c|}
\hline \multirow[t]{4}{*}{ Component } & \multirow{4}{*}{$\begin{array}{l}\text { Retention } \\
\text { time (min) }\end{array}$} & \multirow[t]{4}{*}{ HD } & \multicolumn{4}{|c|}{ SFE pressure } \\
\hline & & & $20(\mathrm{MPa}$ & & $30(\mathrm{MPa}$ & \\
\hline & & & \multicolumn{4}{|c|}{ Temperature } \\
\hline & & & $35\left({ }^{\circ} \mathrm{C}\right)$ & $45\left({ }^{\circ} \mathrm{C}\right)$ & $35\left({ }^{\circ} \mathrm{C}\right)$ & $45\left({ }^{\circ} \mathrm{C}\right)$ \\
\hline Citronellol & 8.76 & 10.29 & 6.11 & 5.67 & 6.07 & 6.48 \\
\hline Nona-1,8-dien-4-ol & 12.26 & 0.20 & 0.48 & 0.49 & 0.57 & 0.61 \\
\hline 6,6-Dimethylbicyclo[3.1.1]hept-2-ene-2-ethanol & 13.30 & 9.12 & 7.12 & 6.85 & 7.16 & 7.14 \\
\hline (Z)-1,1-diethoxyhex-3-ene & 13.72 & 2.11 & 1.39 & 1.21 & 1.44 & 1.52 \\
\hline 2-Methyl-2-phenylpentadecane & 14.96 & - & 0.52 & 0.47 & 0.54 & 0.50 \\
\hline $\begin{array}{l}\text { 1,6-Cyclodecadiene, 1-methyl-5-methylene-8- } \\
\text { (1-methylethyl)-, [S-(E,E)]- }\end{array}$ & 15.40 & 3.21 & 2.78 & 2.67 & 2.73 & 2.81 \\
\hline $\begin{array}{l}\text { 1,3,6,10-Dodecatetraene, } \\
(3 \mathrm{Z}, 6 \mathrm{E}) \text { - }\end{array}$ & 15.72 & - & 0.14 & 0.18 & 0.14 & 0.17 \\
\hline 1-Ethyl-3-vinyl-adamantance & 16.26 & 0.82 & 0.65 & 0.68 & 0.70 & 0.68 \\
\hline $\begin{array}{l}\text { 1,2,3,4-Tetrahydro-4-isopropyl-1,6- } \\
\text { dimethylnaphthalene }\end{array}$ & 17.15 & 3.87 & 2.96 & 2.81 & 3.01 & 3.75 \\
\hline Cada-1(10),3,8-triene & 17.74 & 1.24 & 0.92 & 1.07 & 0.99 & 1.02 \\
\hline 2-(1,3-Butadienyl)mesitylene & 18.34 & - & 0.27 & 0.27 & 0.30 & 0.26 \\
\hline $\begin{array}{l}\alpha-[(3,3-D i m e t h y l-2-i s o p r o p y l o x i r a n y l) e t h y n y l]-\alpha- \\
\text { methylcyclopentanemethanol }\end{array}$ & 18.64 & 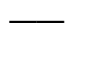 & 0.18 & 0.17 & 0.18 & 0.11 \\
\hline 1,3-di- $n$-Propyladamantane & 19.64 & 1.02 & 0.57 & 0.51 & 0.62 & 0.77 \\
\hline Nona-1,8-dien-4-ol & 22.77 & - & 0.21 & 0.18 & 0.20 & 0.22 \\
\hline 1-Chlorooctane & 23.02 & - & 0.16 & 0.13 & 0.15 & 0.21 \\
\hline $\begin{array}{l}\text { 2,2,6-Trimethyl-1-(3-oxo-1-butenyl)-7- } \\
\text { oxabicyclo[4.1.0]heptane-4-yl acetate }\end{array}$ & 25.58 & & 0.10 & 0.10 & 0.12 & 0.10 \\
\hline $\begin{array}{l}\text { 1-Methylidene-2b-hydroxymethyl-3,3-dimethyl- } \\
\text { 4b-(3-methyibut-2-enyl)-cyclohexane }\end{array}$ & 28.87 & & 0.38 & 0.37 & 0.41 & 0.48 \\
\hline 5-Methyl[1,2,4]triazolo[1,5-a]pyrimidin-7-amine & 29.51 & - & 0.31 & 0.30 & 0.32 & 0.39 \\
\hline Pentadecanoic acid, ethyl ester & 30.72 & 8.75 & 10.21 & 9.81 & 9.88 & 10.20 \\
\hline 9,12-Octadecadienoicacid, methyl ester, $(E, E)$ - & 35.43 & 18.71 & 25.84 & 21.49 & 26.01 & 27.32 \\
\hline 9-Octadecenoic acid (Z)-, ethyl ester & 35.64 & 10.32 & 11.05 & 11.08 & 11.12 & 11.02 \\
\hline Nonadecanoic acid ethyl ester & 36.46 & 1.87 & 1.98 & 1.89 & 1.98 & 1.97 \\
\hline
\end{tabular}


Fig 1 shows the ranges of oil yield obtained by hydrodistillation (HD) and supercritical fluid extraction separately. It was found that the extraction yield was different for the two extraction methods. HD method resulted in lower yield because only those volatile fractions that are part of the volatile oil can be extracted out under this method. On the other hand, SFE showed a higher yield for it can not only extract those volatile components, but also non-volatile ones. All extracted components and their proportions are shown in Table 3.

In products obtained via above two methods, HD method and SFE, (E,E)-9,12-octadecadienoic acid methyl ester, (Z)-9-octadecenoic acid ethyl ester were the most abundant components. The pleasant anise-like odour of the oil could be due to other major compounds like 6,6dimethylbicyclo-hept-2-ene-2-ethanol citronellol (Table 3).

Table 4: Polygonatum odoratum oil yield obtained by hydrodistillation (HD, $\mathrm{n}=2$ ) and supercritical fluid extraction (SFE, $n=5$ )

\begin{tabular}{llllll}
\hline Method & \multicolumn{5}{c}{ Yield (\%) } \\
\hline HD & 0.98 & 0.87 & & & \\
SFE & 1.92 & 1.87 & 1.76 & 1.47 & 1.66 \\
\hline
\end{tabular}

\section{Effect of extraction time and temperature on volatile oil yield}

Under constant extraction pressure of $30 \mathrm{MPa}$, different extraction times were selected to examine the oil yields of Polygonatum odoratum under the temperatures of $35,40,45$ and $50^{\circ} \mathrm{C}$, respectively. The results are shown in Fig 1.

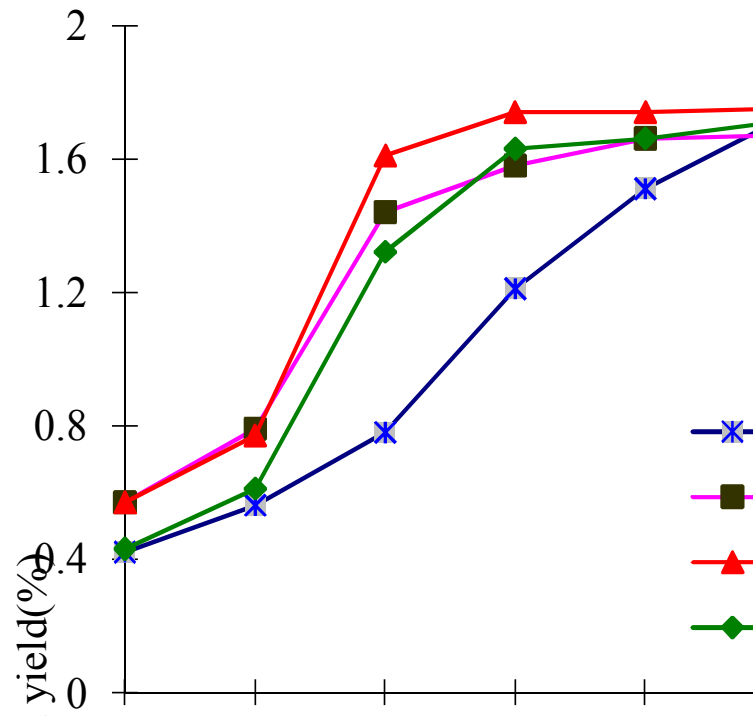

Fig 1: Effect of extraction time and temperature on oil yield from Polygonatum odoratum
From Fig 1, it was found that oil yield increased with the increase in extraction time and the highest yield was obtained at $90 \mathrm{~min}$ under constant extraction pressure of $30 \mathrm{MPa}$. However, the oil yield did not follow any definite pattern with the increase in extraction temperature. The highest oil yield appeared at 45 ${ }^{\circ} \mathrm{C}$ and it then decreased with further increase in temperature.

\section{Effect of extraction pressure on volatile oil extraction}

The test result of this experiment was obtained at extraction temperature of $45^{\circ} \mathrm{C}$, extraction time of $130 \mathrm{~min}$. Under a constant temperature of 45 ${ }^{\circ} \mathrm{C}$, the ultimate oil yield increased with the increase of extraction pressure due to the fact that the density of supercritical $\mathrm{CO}_{2}$ increased with heightened pressure and its solubility also increased as well. Fig 2 reveals that under this experimental condition, the extraction rate of Polygonatum reached a highest rate of $1.94 \%$. A significant surge of oil yield was observed when the pressure rise from 15 to $20 \mathrm{MPa}$ while the yield of oil was slightly increased when the pressure was further lifted from 20 to $30 \mathrm{MPa}$.

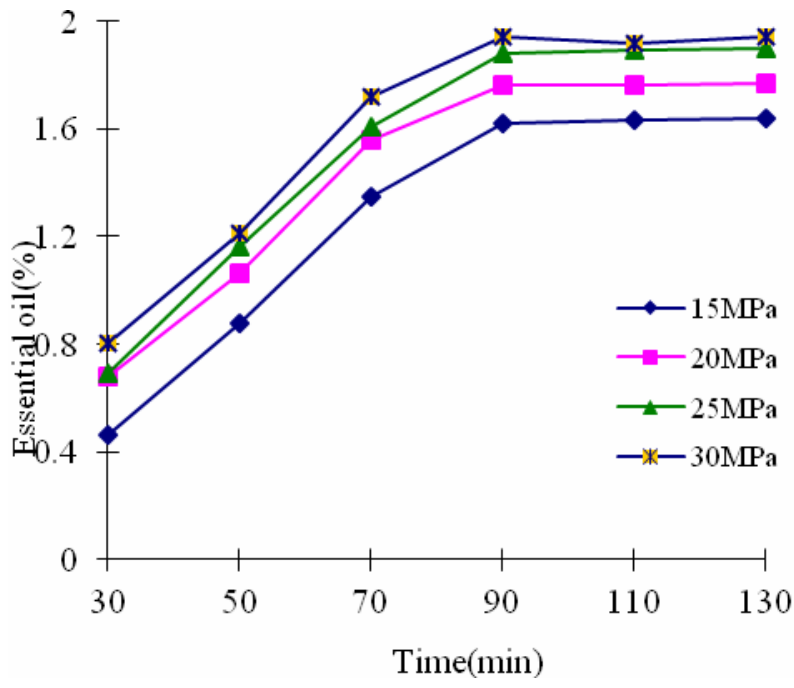

Fig 2: Effect of pressure on oil yield from Polygonatum odoratum

\section{Regression modal and test of significance}

The quadratic polynomial regression equation was established by multiple regression fitting of all test data with Design Expert software (version 7.1.3).

$Y=1.94+0.059 X_{1}+0.17 X_{2}+0.0075 X_{3}-$ $0.017 \mathrm{X}_{1} \mathrm{X}_{2}+0.020 \mathrm{X}_{1} \mathrm{X}_{3}+0.045 \mathrm{X}_{2} \mathrm{X}_{3}-0.00875$ $\mathrm{X}_{1}^{2}-0.20 \mathrm{X}_{2} 2-0.096 \mathrm{X}_{2} 3$ 
The variance analysis of this quadratic regression equation and significance of the coefficient of regression equation are shown in the Table 4. The response surface analytical result of the interaction of the 3 factors analyzed by Design-Expert software as per the multiple regression fitting on the oil yield of Polygonatum essence oil is shown in Fig 4.

Table 4: Analysis of variance (ANOVA) for the fitted quadratic polynomial model

\begin{tabular}{lccccc}
\hline Source & $\begin{array}{c}\text { Sum of } \\
\text { squares }\end{array}$ & DF & $\begin{array}{c}\text { Mean } \\
\text { square }\end{array}$ & $\boldsymbol{F}$-value & $P$-value \\
\hline Model & 0.49000 & 9 & 0.05500 & 48.05 & $<0.0001$ \\
$\mathrm{x}_{1}$ & 0.02800 & 1 & 0.02800 & 24.24 & 0.0017 \\
$\mathrm{x}_{2}$ & 0.23000 & 1 & 0.23000 & 199.96 & $<0.0001$ \\
$\mathrm{x}_{3}$ & 0.00045 & 1 & 0.00045 & 0.39 & 0.5496 \\
$\mathrm{x}_{1} \mathrm{x}_{2}$ & 0.00125 & 1 & 0.00125 & 1.08 & 0.3343 \\
$\mathrm{x}_{1} \mathrm{x}_{3}$ & 0.00160 & 1 & 0.00160 & 1.40 & 0.2747 \\
$\mathrm{x}_{2} \mathrm{X}_{3}$ & 0.00810 & 1 & 0.00810 & 7.11 & 0.3222 \\
$\mathrm{x}_{1}{ }^{2}$ & 0.00322 & 1 & 0.00322 & 0.28 & 0.6112 \\
$\mathrm{x}_{2}{ }^{2}$ & 0.17000 & 1 & 0.17000 & 153.43 & $<0.0001$ \\
$\mathrm{x}_{2}{ }^{3}$ & 0.03900 & 1 & 0.03900 & 34.24 & 0.0006 \\
Residual & 0.00798 & 7 & 0.00114 & & \\
Lack of Fit & 0.00658 & 3 & 0.00219 & 6.26 & 0.0543 \\
Pure error & 0.00140 & 4 & 0.00035 & & \\
Core total & 0.50 & 16 & & & \\
Coefficient & 1.88 & & & & \\
of variation & & \multicolumn{5}{c}{} \\
\hline
\end{tabular}

Table 4 and Fig 3 present the great significance of $X_{2}$ partial regression coefficient, indicating that the highly remarkable effect of pressure on the extraction rate of the essential oil; The significance of $X_{1}$ illustrated the great effect of extraction temperature on the oil yield of Polygonatum essence oil. The partial regression coefficient of $\mathrm{X}_{2}^{2}$ had reached an extreme significance. Fig 4 shows that pressure and temperature are the key factors affecting oil yield. This is consistent with the results of Pan et al $[16,17]$.

The adjusted determinant $R^{2}$ Adj of this model was 0.9529, which showed that this model could explain the variation of response of oil yield. That is to say that this model was well fitted with actual situation and reflected the relationship of between the oil yield and extraction pressure, temperature and time can be well reflected. Thus, the established regression equation could predict the variation of the oil yield with that of each parameter of the superficial $\mathrm{CO}_{2}$.

Through the Design-Expert software analysis, the optimal extraction condition for exacting the essential oil was: extraction pressure of 26.98 $\mathrm{MPa}$, extraction temperature of $50.00{ }^{\circ} \mathrm{C}$ and extraction time of $97.10 \mathrm{~min}$. Considering the convenience of actual operation, the determined process condition for exacting the essential oil was: extraction pressure of $27 \mathrm{MPa}$, extraction temperature of $50{ }^{\circ} \mathrm{C}$ and extraction time of $97.10 \mathrm{~min}$. The predicted theoretical oil yield from this regression equation is $2.04 \%$.

To verify the prediction result, three repetitive tests under the determined optimal process condition acquired through above response surface analysis and a mean extraction rate of $2.02 \% \pm 0.034$, was achieved, basically consistent with the predicted value. This means that this equation fitted well with the actual situation and verified fully the correctness of the established model and showed the suitability of this response surface analysis method in conducting regression analysis and parameter optimization to the superficial extraction process of the essential oil.

\section{Organoleptic description}

The absolutes from SFE extracts showed a pale yellow-yellow colour, having a traditional Chinese medicine natural clean fresh character, resembling the actual plant scent but with the Traditional Chinese medicine note more striking. When the separator pressure was at $6 \mathrm{MPa}$, the extract was a somewhat brownish oily substance, indicating more oil soluble impurities in the oil. When the separator pressure was between $7 \mathrm{MPa}$ and $9 \mathrm{MPa}$, the extract appeared to be a yellowish oily substance and transparent. This suggests more oil substances in the oil. Therefore, the separator pressure between 7 and $9 \mathrm{MPa}$ was adopted in this study. The volatile oil distilled by steam appeared to be slightly cloudy and brownish.

\section{DISCUSSION}

Oil yield did not follow any definite pattern with increase in extraction temperature. The highest oil yield was at $45^{\circ} \mathrm{C}$ and it then decreased with further increase in temperature. This is because superficial fluid density decreases with rise of temperature, causing a decline in the solvent effect of the liquefied $\mathrm{CO}_{2}$. This decline in solvent effect can result in a drop in the solubility of its contents; hence, optimum extraction temperature was determined to be $45^{\circ} \mathrm{C}$. Actual experimental data indicate that the effect of extraction pressure on volatile oil extraction did not correlate linearly with pressure. This may be explained probably by the compressibility of the supercritical $\mathrm{CO}_{2}$, which is higher at low pressure and lower at high pressure. The pressure adopted in this study was $30 \mathrm{MPa}$. 


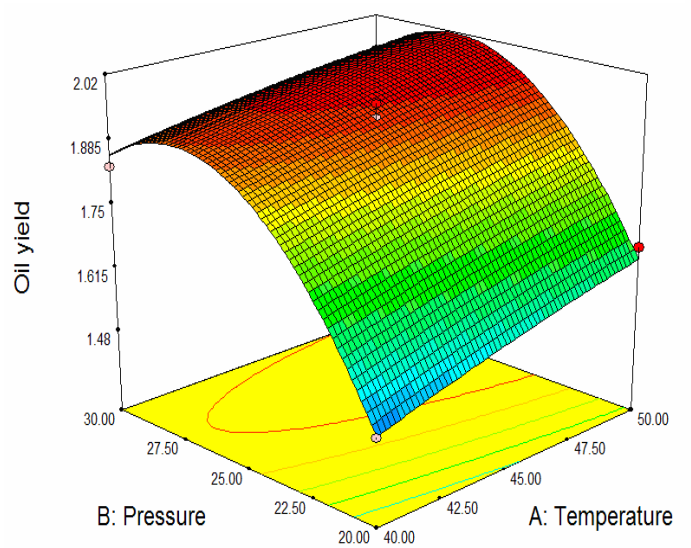

(a) Time: $90 \mathrm{~min}$

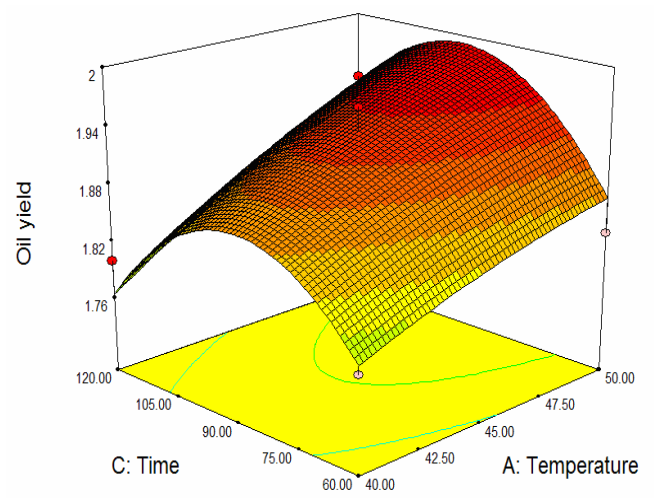

(b) Pressure: $25 \mathrm{Mpa}$

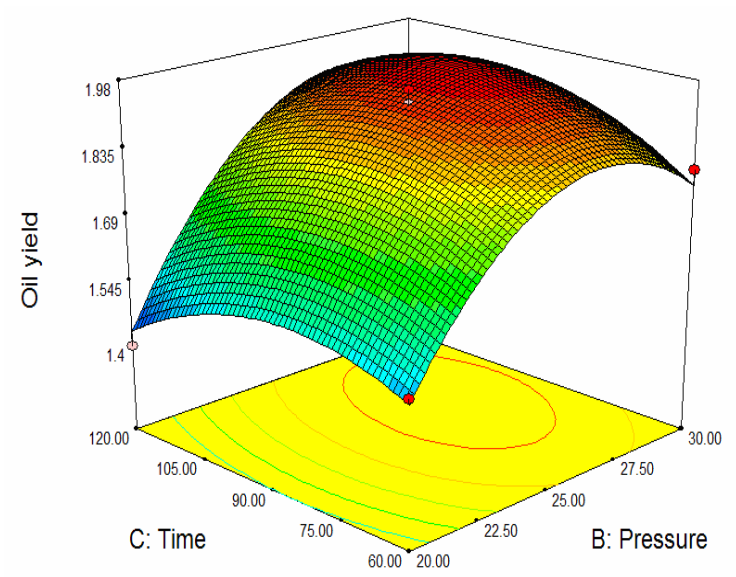

(c) Temperature: $45^{\circ} \mathrm{C}$

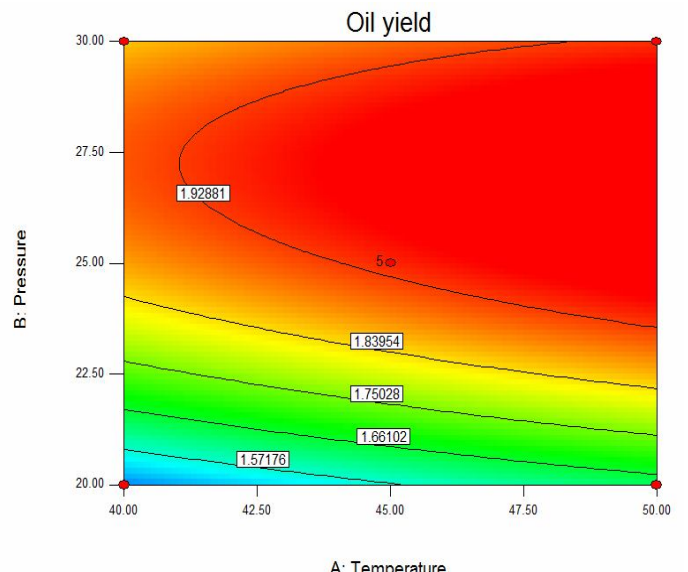

A: Temperature
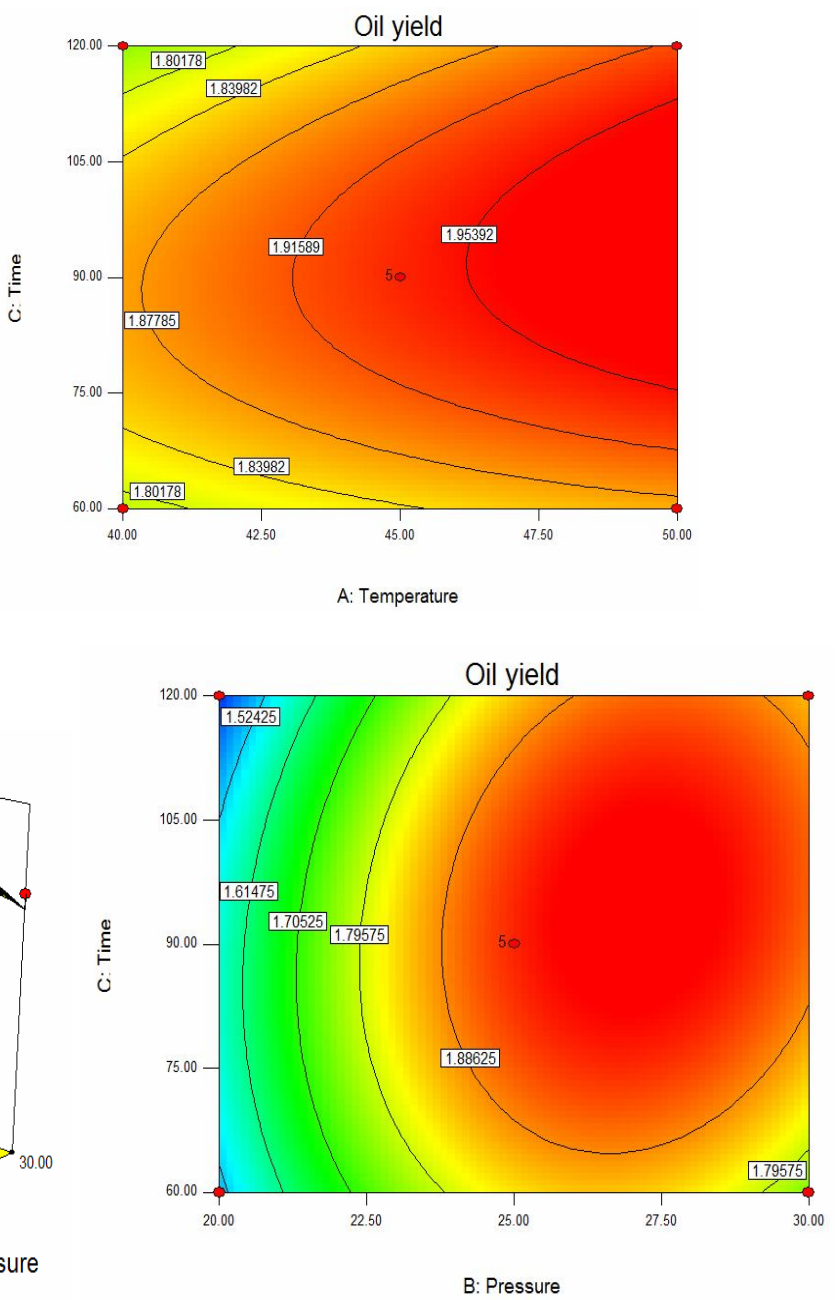

Fig 3: Response surface and contour plots for oil yield from Polygonatum odoratum as in relation to extraction pressure, temperature and time

A small-scale homemade equipment for supercritical extraction was constructed for this work. Compared with the traditional extraction methods, the SFE takes less time and consumes less energy, it has high extraction rates with no organic solvent pollution. Based on GC-MS analysis, it was found that among the 23 chemical compounds in the volatile oil, the content of unsaturated fatty acids was rich. These compounds have a wide range of biological activities with antimicrobial effects. The clean technology of $\mathrm{CO}_{2}$ supercritical extraction was employed to produce a high quality natural 
material that can be used in soft drinks, candy, ice cream, seasoning and health food, etc.

Traditional statistics method often employs either orthogonal design or uniform design. Either of these designs is capable of yielding the best factor combination by taking several factors into account, but they cannot provide an explicit function expression, i.e., polynomial regression equation. Therefore, best factor combination as well as optimal value of response e in the whole area cannot be worked out.

Response surface analysis method is a regression analysis method used to study the interactions of several experimental factors by central composite design. It boasts of advantages of shorter experiment time, high precision in obtained regression equation and the factors can be studied via graphical analysis. Also it can be used to obtain the optimal test factor value in the graphics. In fact, at least two detection methods should be used in identifying $t$ flavoring components and each compound should have its own detection method according to each component's authentic or published sources. It would be more accurate and rigorous if internal or external standard methods are employed in the experiment rather than normalization method for quantitative analysis.

The present work resulted in the determination of optimum extraction conditions and improvement of the content of the volatile oil of $P$. odoratum by optimization of the traditional mathematical statistics method. This study intended was intended to be only a preliminary assessment of the composition of the oil extract, and hence indepth studies are still required in this regard.

\section{CONCLUSION}

The effect of various factors on the oil yield of Polygonatum odoratum is in the following rank order of importance: extraction pressure > extraction time $>$ extraction temperature. Extraction pressure has a significant effect on the extraction process. The optimal parameters obtained via analysis of variance are as follows: extraction pressure, $27 \mathrm{MPa}$; extraction temperature, $50{ }^{\circ} \mathrm{C}$; and extraction time, 97.10 min. Under these conditions the essential oil yield reaches $2.02 \%$. The volatile oil obtained from Polygonatum odoratum has a pale yellow color and intense fragrant aroma.

\section{ACKNOWLEDGEMENT}

This work was financially supported by Program for Liaoning Excellent Talents in University (LNET) and Liaoning Natural Science Foundation of China (2013020077).

\section{REFERENCES}

1. Lan GH, Chen HX, Wang ZS, Zhang WJ, Zhang LK. Extraction of Polygonatum odoratum polysaccharides using response surface methodology and preparation of a compound beverage. Carbohydr Polym 2011; 86: 117-180.

2. Deng $Y F$, He $K$, Ye $X L$, Chen $X$, Huang J, Li XG, Yuan $L J$, Jin $Y L$, Jin $Q, L i P P$. Saponin rich fractions from Polygonatum odoratum (Mill.) Druce with more potential hypoglycemic effects. J Ethnopharmacol 2012; 141: 228-233.

3. Yang $Y, X u H L$, Zhang ZT, Liu JJ, Li WW, Ming $H$, Bao JK. Characterization, molecular cloning, and in silico analysis of a novel mannose-binding lectin from Polygonatum odoratum (Mill.) with anti-HSV-II and apoptosis-inducing activities. Phytomedicine 2011; 18: 748-755.

4. Rafi MM, Vastano BC. Identification of a structure specific $\mathrm{Bcl}-2$ phosphorylating homoisoflavone molecule from Vietnamese coriander (Polygonatum odoratum) that induces apoptosis and $G 2 / M$ cell cycle arrest in breast cancer cell lines. Food Chem 2007; 104: 332340.

5. Kim JS, Kim JC, Lee S, Lee BH, Cho KY. Biological activity of L-2-azetidinecarboxylic acid, isolated from Polygonatum odoratum var. pluriflorum, against several algae. Aquat Bot 2006; 85: 1-6.

6. Liu B, Zhang B, Min MW, Bian HJ, Chen LF, Liu Q, Bao JK. Induction of apoptosis by Polygonatum odoratum lectin and its molecular mechanisms in murine fibrosarcoma L929 cells. Biochim Biophys Acta 2009; 1790: 840-844.

7. Qian $Y$, Liang JY, Qu W, Che YY. Two new homoisoflavanones from Polygonatum odoratum (Mill.) Druce. Chin Chem Lett 2010; 21: 706-708.

8. Shua XS, LV JH, Tao J, Li GM, Li HD, Ma N. Antihyperglycemic effects of total flavonoids from Polygonatum odoratum in STZ and alloxan-induced diabetic rats. J Ethnopharmacol 2009; 124: 539-543.

9. Pourmortazavi SM, Hajimirsadeghi SS. Supercritical fluid extraction in plant essential and volatile oil analysis. $J$ Chromatogr A 2007; 1163: 2-24.

10. Grosso C, Coelho JP, Pessoa FLP, Fareleira JMNA, Barroso JG, Urieta JS, Palavra AF, Sovova $H$. Mathematical modeling of supercritical $\mathrm{CO}_{2}$ extraction of volatile oils from aromatic plants. Chem Eng Sci 2010; 65: 3579-3590. 
11. Sonsuzer S, Sahin S, Yilmaz L. Optimization of supercritical $\mathrm{CO}_{2}$ extraction of Thymbra spicata oil. $J$ Supercrit Fluids 2004; 30: 189-199.

12. Cao $H$, Xiao JB, Xu M. Comparison of volatile components of Marchantia convoluta obtained by supercritical carbon dioxide extraction and petrol ether extraction. J Food Compost Anal 2007; 20: 4551.

13. Zizovic I, Stamenić $M$, Orlović A, Skala D. Supercritical carbon dioxide extraction of essential oils from plants with secretory ducts: Mathematical modelling on the micro-scale. J Supercrit Fluids 2007; 39: 338-346.

14. Hamdan S, Daood HG, Markus MT, Illés V. Extraction of cardamom oil by supercritical carbon dioxide and sub-critical propane. J Supercrit Fluids 2008; 44: 25 30.
15. Wei ZJ, Liao AM, Zhang HX, Liu J, Jiang ST. Optimization of supercritical carbon dioxide extraction of silkworm pupal oil applying the response surface methodology. Bioresour Technol 2009; 100: 42144219.

16. Wei ZJ, Zhou LC, Chen H, Chen GH. Optimization of the Fermentation Conditions for 1-Deoxynojirimycin Production by Streptomyces lawendulae Applying Response Surface Methodology. Int J Food Eng 2011; 7: article 16.

17. Pan WJ, Liao AM, Zhang JG, Dong Z, Wei ZJ. Supercritical Carbon Dioxide Extraction of the Oak Silkworm (Antheraea pernyi) Pupal Oil: Process Optimization and Composition Determination. Int $\mathrm{J}$ Mol Sci 2012; 13: 2354-2367. 